\title{
TRAS LAS HUELLAS DE KANT O SOBRE EL SER Y EL CONOCER EN ARQUEOLOGÍA (OFRENDA FILOSÓFICA AL PROFESOR VALLESPÍ)
}

\author{
FOLLOWING THE TRACKS OF KANT ABOUT BEING AND KNOWING IN \\ ARCHAEOLOGY (PHILOSOPHICAL OFFERING TO DR. VALLESPÍ) \\ por
}

ENRIQUE GARCÍA VARGAS

RESUMEN Este trabajo trata acerca de la Arqueología y su constitución como ciencia desde una perspectiva ontológica que pretende no ser metafísica. Para ello, parte de una lectura posible de Kant muy alejada de la habitual en los manuales de Historia de la Filosofía al uso.

\begin{abstract}
This paper deals with Archaeology and its constitution as a Science from an ontologic point of view that tries not to be metaphysic. It works with a underestanding of Kant's texts that is different of that in use in standard manuals of History of Philosophy.
\end{abstract}

Palabras claves Arqueología, Ciencia, Filosofía, Teoría Trascendental.

Key words

Archaeology, Philosophy, Science, Transcendental Theory.

\section{A MODO DE OFRENDA Y DE JUSTIFICACIÓN ${ }^{1}$}

Quienes hayan tenido la inmensa fortuna de recibir el magisterio de profesor Vallespí en las aulas universitarias, en nuestro caso como alumno de primero de carrera, no podrán sino coincidir con nosotros en la consideración de que dicho magisterio no se circunscribió nunca a la estricta materia cuya docencia tan brillantemente impartió durante años y que tuvo siempre que ver con aquello que cariñosamente llamábamos "las piedras".

1. Agradecemos vivamente a G. Chic García, Ma . L. de la Bandera Romero, O. Arteaga Matute, J. L. Escacena Carrasco, J. I. Cano Montero y L. García Sanjuán que hayan tenido la paciencia de leer el texto preliminar de este trabajo y que nos hayan hecho cuantas sugerencias estimaron oportunas. Como ellos mismos podrán comprobar, no las hemos incorporado todas, por lo que asumimos completamente las críticas que del tenor del artículo puedan derivarse por parte de terceros. 
Más allá, en efecto, de una serie de contenidos en cuya exposición fue siempre especialmente riguroso y "científico" como corresponde a su talla internacionalmente reconocida de paleolitista, el profesor Vallespí supo y quiso siempre abrir a sus alumnos, en consonancia ahora con su categoría como persona, una perspectiva de comprensión de las cosas a la que tal vez cuadraría el calificativo de "humanista" ${ }^{2}$, una perspectiva que era radicalmente nueva y especialmente atractiva para quienes nos iniciábamos entonces en la Historia y por la que D. Enrique Vallespí sintió una especial predilección como representante que es de una forma de ver las cosas heredada de sus maestros y que, desgraciadamente, parece estar destinada a desaparecer de la Universidad española y de la enseñanza en general si no ponemos remedio.

Es tal vez gracias a ello, a esta especial manera de ver las cosas, que aquellos que hemos seguido una carrera alejada del estudio de la Prehistoria hayamos sentido una especial vinculación intelectual con quien un día fue nuestro profesor y que, hoy, sin dejar por ello de ser maestro, es también compañero en las tareas docentes del Departamento de Prehistoria y Arqueología.

Y es también por esto que consideramos oportuno ofrecerle en este su homenaje un trabajo que no tenga que ver con especialidad alguna, sino más bien con aquello que desde lo que todas pueden ser contempladas, un trabajo teórico que pretende abordar ciertos problemas específicos de la Arqueología desde un punto de vista que quiere ser filo-sófico.

La variante gráfica que recogemos para la palabra filosofía ${ }^{3}$ encuentra, como se verá, su pertinencia en el convencimiento de que se trata de una visión no enraizada en ningún tipo de metafísica, sino en aquello que, creemos, debe considerarse como lo específicamente filosófico (un interés por el saber), en aquello que, pensamos, debe consistir, como diría Heidegger, en un "sobreponerse a la metafísica" (cit. en Gadamer 1998).

En nuestro particular visión acerca de en qué consiste dicho "sobreponerse a la metafísica" hemos considerado pertinente, al menos por el momento, no abandonar de forma explícita los postulados de la dogmática clásica, si bien en la versión depurada que puede encontrarse en cierta lectura de Kant. No se trata tan sólo de retener el mínimo de dogmatismo necesario para no caer en el dogmatismo, sino, sobre todo, de defender una cierta concepción de la Arqueología como ciencia incompatible en principio con los desarrollos más recientes de una teoría "posmoderna" que, como tal, hace imposible fundamentar racionalmente la práctica arqueológica (Lull et alii 1990) y niega su posibilidad (a pesar de ciertos intentos recientes por conciliar lo irreconciliable), incluso antes de que haya sido posible establecer en qué consiste esta posibilidad .

No se trata, por tanto, de presentar una versión cerrada y eterna de la cuestión trascendental aplicada a la Arqueología, sino más bien de proponer un enfoque fenomenológico que se contenta con ir de las cosas a su conocimiento. En tanto se niegue la fecundidad de dicho enfoque, se estarán minando las bases de una actitud que asumimos como "logocéntrica" a su manera ${ }^{4}$. Pero de estas cuestiones es preciso tratar en otro lugar y, lo más seguro, sobre unas bases que, en principio, no nos negamos a considerar, pero que tal vez no puedan encontrar aquí un acomodo fácil.

2. Damos a este término el significado general que posee y no el filosófico, que tiene una serie de connotaciones no asumidas por el autor de estas líneas (Cfr. Althusser 1976).

3. Variante que recogemos de C. Fernández Liria (1992), aunque es probable que este autor considerara abusivo el uso que hacemos de ella.

4. Resulta ser logocéntrica a su manera porque, en principio, niega la posibilidad de considerar el ser, el logos, como algo concreto y tangible y lo concibe como la clase de "nada" en que consiste la estructura de lo conocido (infra), pero, sobre todo, porque se instala en el centro del debate logocéntrico proponiendo una visión de en qué ha consistido este debate a través de la reinterpretación de ciertos tópicos del mismo que considera mal explicitados. En cierto modo, de lo que se trata es de volver sobre ciertos decires como tales decires, asumiendo su contenido y proponiendo una lectura de los mismos que sólo es posible desde el interior del logocentrismo. 


\section{UNA CUESTIÓN FILOSÓFICA: ¿CIENCIA VERSUS CREACIONISMO?}

En la investigación que proponemos nos servirá de partida, aunque más bien a modo de excusa, un trabajo reciente, por lo demás bastante notorio, de José Luis Escacena (e. p.) en el que el autor ha expuesto, por primera vez en nuestra lengua que tengamos noticia, las bases de lo que desde su perspectiva debe ser una aproximación evolucionista a la Arqueología.

Las líneas que siguen no pretenden, por tanto, de ningún modo ser una especie de exégesis de lo planteado por este autor en el citado trabajo o en algún otro. Tampoco quieren ser una respuesta o una crítica a lo mismo 5 .

Lo primero resultaría gratuito, por cuanto abundaría en lo ya expuesto por él, probablemente con bastante más solvencia de la que nosotros podamos pretender; lo segundo escapa simplemente a nuestra intención, pues el objetivo que nos hemos marcado en este artículo no es en modo alguno el de plantear objeciones a la teoría evolucionista en su "versión" arqueológica tal como la entiende Escacena.

Lo que aquí pretendemos, en consonancia con nuestra formación y posibilidades, es una cosa diferente y además bastante más simple: se trata tan sólo de plantear algunas reflexiones a propósito de la pertinencia, en tanto que enunciado, de aquello que creemos entender como tesis central del artículo de Escacena: la constatación de que la Ciencia (y con ella la Arqueología) sólo puede ser evolucionista, en tanto que lo opuesto al evolucionismo es el creacionismo.

Vaya por delante que en su planteamiento general suscribimos dicha afirmación. Otra cosa es que consideremos que los presupuestos de la ciencia evolucionista, si es que es posible pensar en una ciencia que no lo sea, puedan aplicarse a la Arqueología sin modificaciones conceptuales sustantivas, modificaciones que por otra parte están implícitas en toda la "historia" de la Ciencia, incluida aquella que es anterior a Darwin.

Pero hemos prometido no entrar a fondo en la "cuestión evolucionista", sino más bien investigar sobre la pertinencia (validez) como tal del enunciado: "la Ciencia (y con ella la Arqueología) es evolucionista" o mejor de su equivalente sensu contrario: "la Ciencia (y con ella la Arqueología) no es creacionista".

Convendrá aclarar al respecto que introduciendo la expresión "validez del enunciado" pretendemos restringir el campo de análisis del mismo a una perspectiva filosófica.

Perspectiva filosófica (filo-sófica) no equivale aquí a algo así como a toda la tradición filosófica o, dicho de otro modo, a toda la Historia de la Filosofía, entendiendo Filosofía como el conjunto de saberes y decires que constituyen lo que se suele llamar "pensamiento occidental". Ello es simplemente imposible. Y no sólo porque la Historia de la Filosofía como algo unitario y consistente (internamente cohesionado) probablemente no existe más que en el interior de la Enciclopedia de las Ciencias filosóficas de G. W. F. Hegel (Enz), sino también y sobre todo porque el problema de la validez como tal problema es una cuestión filosófica estrictamente moderna, una cuestión que tiene su acta de nacimiento en el Discurso del Método cartesiano y que de algún modo ha sido desarrollada con mejor o peor fortuna por el pensamiento posterior a Descartes (Martínez Marzoa 1994).

La cuestión de la validez del enunciado viene a ser para el pensamiento moderno, o para cierta parte del pensamiento moderno que se inicia precisamente con Descartes, otra forma, una forma esencialmente moderna, de plantear el problema filosófico del ser (ibídem). Ello es así porque se establece a partir de Descartes que el ser no consiste más, como quisieron los filósofos griegos, en la referencia a algo exterior, en la adecuación del decir a una validez externa en la que precisamente reside el ser, sino más bien que la validez y el ser resultan la misma cosa.

5. Ha sido tal vez J. M. Vicent García (1992) quien mejor ha sintetizado las críticas posibles a los planteamientos evolucionistas en Arqueología, con serios argumentos que, no obstante, no podemos compartir en su integridad. 
Un decir válido equivale en estas condiciones a un decir que dice lo que las cosas son o, mejor, que coincide sustancialmente con el ser de las cosas, con su eîdos, su forma, su possibilitas (diría la dogmática clásica y con ella Kant refiriéndose a lo que nosotros conocemos como estructura).

Pero ese eîdos, esa forma, esa possibilitas no estará ya en el sujeto del enunciado ni en el predicado, sino en ambos lugares a la vez, es decir, en la cópula, en el verbo que dice en qué consisten las cosas, en el "es", en la syntesis o apóphansis a que queda reducida la cópula del enunciado (ibídem).

Resulta evidente, por lo demás, que esto sólo es posible después del trabajo conceptual que la sistemática aristotélica vertió sobre el concepto de ser, una reducción que marcó el fin de la filosofía clásica griega y que vino favorecida por el propio desarrollo de la lengua griega vulgar (ibídem) .

A partir de Aristóteles (y no antes, aunque Aristóteles quedaría a todos los efectos englobado en el "antes")

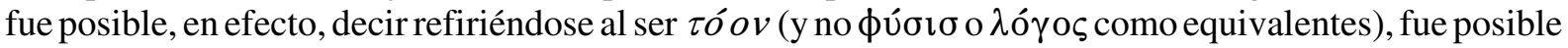
reducir toda la complejidad del ser a una mera cuestión de adecuación, de correspondencia entre un sujeto y su predicado, fue posible, en definitiva, circunscribir "ser" a una cópula o, lo que es lo mismo, a algo así como un término vacío que no consiste en nada concreto más allá de la simple relación que se expresa en "todo A es B".

Al decir que pretendemos examinar el enunciado "la Ciencia (y con ella la Arqueología) no es creacionista" desde una simple perspectiva filosófica, estamos diciendo en verdad que queremos (re)examinar dicho enunciado desde el punto de vista de su validez en cuanto tal, es decir, en los términos en que supuestamente Ciencia y creacionismo establecen una relación que consiste en que una cosa no es en ningún caso la otra, o dicho de otro modo: en los términos en que el concepto de "creacionismo" no resulta en modo alguno pertinente (válido) para determinar en qué consiste (qué es) el sujeto "Ciencia".

No se trata, por supuesto, de un simple análisis gramatical, puesto que ya se ha establecido el carácter de "conjunto vacío" que atribuimos (que atribuye la Filo-sofía desde Aristóteles) al término ser, un término que no puede consistir ni tan siquiera en su función como elemento gramatical, un término cuyo ser, valga la redundancia, consiste paradójicamente en su no-ser, en su posible supresión sin que la validez del enunciado se resienta, aunque, en términos ahora sí estrictamente gramaticales, dicha supresión deba ser marcada por una coma (Ciencia, evolucionismo, o bien, Ciencia, no creacionismo).

Dicho lo cual, no podemos menos que asentir con G. Gadamer (1998) en el hecho de que para comenzar a pensar, es decir, para hacer Filosofía (aunque sea la modesta filosofía que torpemente enjaretamos), es imprescindible comenzar por escuchar lo que dicen las palabras. Son en este caso tres las palabras que reclaman nuestra atención: Ciencia (y en la medida que la Arqueología lo sea, también Arqueología), evolucionismo y creacionismo. La primera, se nos aparece como sujeto; las otras dos, como enunciados excluyentes que expresan la possibilitas, la estructura, el ser de la Ciencia.

En realidad analizaremos tan sólo dos de ellas: Ciencia y creacionismo. En cuanto a lo que quiera decir evolucionismo, remitimos de nuevo al magnífico trabajo del profesor Escacena (e. p.) con la bibliografía allí citada. Por lo que hace a la palabra "es", queda dicho que en el contexto filosófico en el que pretendemos movernos no equivale a un lexema, sino a una relación (una relación universal y necesaria en la que además consiste toda la validez del enunciado, pero al fin y al cabo una relación), por lo que requerirá nuestra atención al hilo de la exposición, sin que precise de un apartado específico. 


\section{SOBRE LA POSIBILIDAD DE LA CIENCIA (Y CON ELLA, DE LA ARQUEOLOGÍA) Y SU SEPARACIÓN DE LA FILOSOFÍA ${ }^{6}$}

Hay, en principio, muchas maneras de definir la Ciencia lo que no significa desde luego que todas sean igualmente válidas y mucho menos que cualquier cosa sea una definición de Ciencia.

Las definiciones más extendidas de Ciencia, desde la más rigurosa, que considera como tal aquel decir caracterizado en último extremo por la cuantificación y la formalización en lenguaje analítico y matemático, a las más relajada, que considera como tal aquel decir determinado por la racionalidad, entendiendo ahora racionalidad no como cuantificación y formalización matemática, sino como conjunto de tesis (formales o no) cuya validez procede de la circunstancia de que son compartidas por un cuerpo de científicos (paradigma), tienen en común el hecho de que son definiciones "vulgares" de la Ciencia.

"Vulgar" debe entenderse en este contexto no como poco refinadas o poco adecuadas al pensamiento, sino más bien como no filosóficas, como correspondientes al orden de la doxa u opinión (Havelock 1994, Bachelar 1985, Albiac 1979, Fernández Liria 1992, Ídem 1998) más que al del ser de la Ciencia. Son definiciones no filosóficas en el sentido en que venimos aquí considerando la palabra Filo-sofía, no como equivalente de metafísica, sino como investigación que pretende establecer el ser de las cosas, su morfée, su eîdos, su possibilitas. Son, en definitiva, definiciones poco filosóficas en el único sentido posible para la Filo-sofía: en el sentido de que no definen la Ciencia por referencia a sus elementos constitutivos, a su ser.

Enunciados del tipo, pongamos por caso, de "la Ciencia es en último extremo cuantificación y formalización" (cualquier cosa que sea lo que se pretenda decir con el término formalización) aun presentando una estructura sintáctica que parece adecuada al conocimiento (“A es B”) no son más que tautologías, expresiones vacías y circulares, pues más que caracterizar al sujeto por aquello que en efecto es, lo que hacen en realidad es referir a un concepto que funciona gramaticalmente como sujeto un conjunto no estructurado de notas (que son a su vez otros tantos conceptos) que de antemano se suponen contenidas en él.

No hay aquí por ningún sitio explicitación de la estructura interna de la Ciencia, de su eîdos, de su posibilidad, sino más bien "meros conceptos" que funcionan como conjuntos no estructurados de notas. Esta misma ausencia de estructura supone un impedimento para que el predicado actúe a modo de regla de constitución del sujeto, es decir, hace imposible que esos mismos conceptos abandonen su condición de "meros conceptos" y se constituyan en otras tantas condiciones de posibilidad del ser de la Ciencia.

Decir "la Ciencia es en ultimo extremo cuantificación y formalización" no supone, en definitiva, añadir conocimiento alguno a lo que de antemano se sabía, pues no es más que una subsunción en un universal (Ciencia) de aquellas notas que se consideran constitutivas de dicho universal.

Lo mismo vale para la expresión "la Ciencia viene a ser un conjunto cohesionado de tesis constitutivas de paradigma", en tanto que el concepto paradigma está incluido en el de conjunto cohesionado de tesis y éste a su vez en el de Ciencia.

Decididamente, si alguna definición ha de dar cuenta de las condiciones de la possibilitas de la Ciencia, si alguna definición ha de dar cuenta de la estructura de la Ciencia en cuanto tal (no de esta ciencia o aquella en particular, sino de la Ciencia en cuanto tal) esta definición debe pretender explicitar el ser de la Ciencia no a través de meros conceptos, sino mediante el tipo de operaciones que son relevantes para el conocimiento.

Desde esta perspectiva, tal vez sea más acertado establecer que la Ciencia consiste en un saber sobre las cosas, sobre cada cosa en particular, atento a lo que las cosas son. Las ciencias vendrían a ser, por tanto, el conjunto de decires en que reside el ser de las cosas (entes), decires presididos o estructurados por un criterio homogéneo de verdad o de legitimidad.

6. Tal vez incurramos a menudo en este apartado en uno de los vicios más recurrentes del diletantismo filosófico: la pasión por definir aquello que a menudo es ya en sí una definición (Gadamer 1998). A pesar de todo, hemos preferido no alterar sustancialmente su contenido.

ISSN: 1133-4525 ISSN-e: 2255-3924

SPAL 9 (2000)

http://dx.doi.org/10.12795/spal.2000.i9.29 
Puede causar extrañeza que la definición que propusimos más arriba para Filo-sofía se aplique, mutatis mutandis, a la Ciencia: un decir legítimo acerca de las cosas, pero debe recordarse que es precisamente con Aristóteles cuando queda abierta la posibilidad de hablar siquiera gramaticalmente, de algo así como el "ser", siendo, en consecuencia, y precisamente gracias a esa posibilidad, el pensamiento que nosotros llamamos helenístico, el que inaugura la perspectiva de la Ciencia.

Resulta, sin embargo, por utilizar expresiones escolásticas, que aquello que estaba en potencia ya en el helenismo no se plasmará en acto hasta la modernidad, hasta que la Ciencia, desgajada de la Filosofía precisamente en virtud del $\tau o ́ o ́ v$ aristotélico, sea capaz de plantear un criterio homogéneo de validez para todo saber sobre el ser de las cosas, independientemente de que ella misma sea o no sea capaz de reconocer explícitamente este criterio de validez.

Lo que tratamos de expresar no se puede tal vez formular con palabras más certeras que las utilizadas por Heidegger al respecto de la diferencia entre Ciencia y Filosofía. Esta diferencia radica según Heidegger (cit. en Fernández Liria 1998) en que la Ciencia se ocupa de las cosas y nada más, siendo este nada más el objeto específico de la Filosofía. Por descontado que este nada más no viene a ser algo parecido a la metafísica, a una esencia oculta, a un ser profundo de las cosas o a la cosa-en-sí (Ding an sich). El nada más significa en este contexto el ser de las cosas, aquello en que consiste, en general, su criterio de validez.

El nada más de las cosas se enfrenta, pues, a las cosas mismas como lo ontológico se pone enfrente de lo óntico, como el ser se contrapone a lo ente mismo. Ontológico quiere decir aquí lo referido al ser, lo constitutivo de lo ente, de su forma, de su esencia, de su eîdos en definitiva. Lo ontológico reside, por tanto, en el "es" del enunciado, en la cópula, en esa nada que da cuenta de la síntesis entre sujeto y predicado y que no añade al sujeto más que el conocimiento de lo que el sujeto es.

En este orden de cosas, la Ciencia y la Filosofía comparten, pues, el negocio del conocer, de la legitimidad del conocer. Pero mientras que la Ciencia aborda la cuestión desde el lado de lo óntico (conociendo qué es esto y aquello en tanto que esto o aquello), la Filosofía adopta la perspectiva de lo ontológico (conociendo

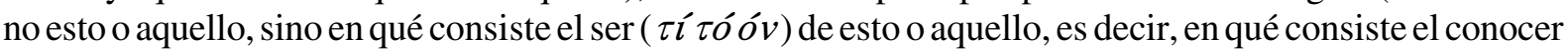
mismo. Éste y no otro es el trasfondo de la tan traída y llevada "cuestión trascendental" kantiana (Martínez Marzoa 1989).

La cuestión trascendental, al interrogar, pues, acerca de en qué consiste el ser (y sólo en este sentido puede considerarse metafísica), pone sobre la mesa la pregunta por la legitimidad del conocer, por la validez cognoscitiva, por las condiciones de la possibilitas del conocimiento. Resulta entonces que en la perspectiva de la Filosofía, y no estrictamente en la de la Ciencia, se produce una coincidencia casi perfecta entre lo ontológico y lo epistemológico, como opuestos a la realidad efectiva, que equivaldría a lo óntico, de cuya validez se ocupa la Ciencia (pero uide Fernández Liria1992) ${ }^{7}$.

Resumiendo: la Ciencia se afana, desde una perspectiva óntica, en establecer las condiciones de la posibilidad de las cosas en cuanto cosas (la estructura, el eîdos, el ser de las cosas como tales cosas), mientras que la Filosofía interroga por la cuestión trascendental, una cuestión que consiste en ocuparse de las condiciones de posibilidad del ser en que consiste el conocer válido.

\section{IV. ¿ES LA CIENCIA (Y CONELLA LA ARQUEOLOGÍA) CREACIONISTA? RELATO DE UNA APARENTE INCONSECUENCIA}

La respuesta de Kant al respecto de la cuestión trascendental es conocida (KrV): las condiciones de posibilidad del conocimiento en cuanto tal conocimiento constituyen el apriori. Es decir, que el conocimiento es posible a priori, antes de la experiencia, pero este antes tiene el sentido no de lo cronológico (orden

7. Para quien, al menos parcialmente, también la ciencia se ocupa de cuestiones ontológicas. 
del tiempo, orden en el que todo conocimiento comienza con la experiencia), sino el de lo lógico (orden de la deducción, en el que todo conocimiento es anterior a la experiencia) ${ }^{8}$.

Conviene al respecto de lo dicho recordar que conocimiento no significa aquí tan sólo un contenido concreto, un conocimiento de esto o de aquello (lo óntico), sino que conocimiento quiere decir también la forma de la validez en que consiste el conocer (lo ontológico). Afirmar que la forma del conocer consiste en el apriori viene a decir pues que el conocimiento es a priori posible y no estrictamente que el conocimiento es posible a priori (Martínez Marzoa 1989).

La diferencia entre una construcción gramatical y otra es la que va de considerar (segundo caso) que la cuestión trascendental consiste en la determinación de la forma en que son posibles ciertos conocimientos que, a pesar de ser conocimientos, lo son a priori (v. g., los que proporciona la física matemática) ${ }^{9}$, en cuyo caso lo que haremos será fundamentar una formas histórica de conocimiento cuya superación implica a su vez la de su fundamentación, a contemplar (primer caso) las formas concretas de conocimiento como ejemplos históricos de aquello en que consiste el conocer (en ser a priori).

Sólo en este último caso se abre la posibilidad de explicitar una validez, por decirlo de algún modo "universal", indiferente en principio a sus propios contenidos válidos ${ }^{10}, \mathrm{o}$ sea, a las ciencias particulares que serán tales en cuanto, como la matemática o la física, funcionen a prior $^{11}{ }^{11}$. Todo ello no es más que una forma específicamente filosófica de decir que el conocimiento (como validez) tiene en sí una posibilidad, tiene una forma, una estructura (el apriori) independiente de su contenido concreto, y que, por ello, cualquier contenido concreto del conocimiento (Ciencia) viene a ser válido en virtud de la posibilidad del apriori.

Pero el cocimiento válido, tanto en su versión general ontológica (Filosofía), como en su versión particular óntica (Ciencia) no es un conocimiento que se da en el hombre como sujeto unitario de representaciones.

8. Experiencia no debe tomarse aquí en el sentido psicológico de afección externa, sino el sentido objetivo de contenido válido cuya validez consiste en que forma contexto, un único contexto válido, con el conjunto de las experiencias posibles.

9. Este es el enfoque tradicional de la doctrina de Kant, la que han impuesto en la literatura filosófica en español los textos de "kantianos" tan eminentes y brillantes como M. García Morente (1980), y la que continúa siendo hegemónica aún en nuestros días entre los comentaristas españoles (Pacho 1999). Aunque, en sí, no puede decirse que esta perspectiva "subjetivista" constituya un tratamiento inadecuado de los escritos de Kant, especialmente de la Crítica de la Razón Pura, es en parte incompleto frente a la lectura más amplia que seguimos y que ha sido planteada en español tan sólo por F. Martínez Marzoa (1989, 1994), quien profundiza en la línea inaugurada por M. Heidegger (1977).

10. Las reminiscencias spinozistas de estos planteamientos, al respecto especialmente de la Sustancia como ámbito del ser (validez) y una vez más en contra de las interpretaciones al uso, son evidentes, aunque seguramente es Kant el primero que acierta a formularlos "en sus justos términos" y sin necesitar para nada de Spinoza.

11. Existe a nuestro entender un enorme malentendido acerca de la legitimidad teórica de la física newtoniana por contraposición a una teoría de la relatividad que habría supuesto su disolución. La física clásica sigue manteniendo su validez en cuanto sus postulados matemáticos (a priori) siguen rigiendo para la clase de fenómenos con que se enfrenta. Su incapacidad para explicar otros muchos fenómenos no se deriva del hecho de que no considere ciertas observaciones o las pase por alto al no poder dar cuenta de ellas, sino más bien a que carece de elementos matemáticos (a priori) suficientes para poder construir dichas observaciones. En todo esto suele funcionar el prejuicio de que las cosas son algo en sí, tienen una esencia interna que la ciencia se limita a poner de manifiesto a través de la experimentación, como si la experimentación, en su propia asepsia no fuera ya una primera forma de enfrentarse a las cosas sin considerarlas cosas-en-sí para el conocimiento, como si los instrumentos de la ciencia empírica no fueran ya algo así como conceptos cosificados (Bachelard 1985) cuya única función es poner de manifiesto el ser (no el ser-en-sí, sino la estructura, la forma) de las cosas. Los logros de Einstein sólo fueron posibles, en efecto, y descontada la "genialidad" del propio Einstein, porque contaba con unas posibilidades analíticas (a priori) infinitamente más potentes que Newton, pero que no hacían tabla rasa con la matemática anterior, sino que la incluía en su seno. Un problema distinto es el planteado por una física cuántica cuyas propuestas resultaron incómodas para el propio Einstein. Es probable que todo cuanto sostenemos en este trabajo (objetividad, conocimiento de la realidad, independencia del observador y del mundo) resulte inadecuado a la luz de los postulados de la física cuántica, pero no es menos cierto que son ideas con las que se puede trabajar dentro de los "límites" del conocimiento racional y a condición de que reconozcamos la finitud de éste y no pretendamos poseer el absoluto, lo que resulta ser precisamente uno de los ejes de nuestra argumentación. Cfr. López Borgoñoz 1995. Agradecemos especialmente al Prof. J. L. Escacena el habernos hecho recapacitar acerca de esta problemática.

ISSN: 1133-4525 ISSN-e: 2255-3924

SPAL $9(2000)$

http://dx.doi.org/10.12795/spal.2000.i9.29 
La expresión "nuestro conocimiento" que a menudo utiliza Kant $(\mathrm{KrV})$ para referirse al conocimiento como validez no indica nada parecido a un tipo de conocimiento propio del sujeto humano, o no indica fundamentalmente eso ${ }^{12}$. A lo que se opone en realidad "nuestro conocimiento" es al conocimiento divino, por cuanto "nuestro conocimiento" es en principio un conocimiento finito (Fernández Liria 1998).

Finito debe entenderse como contrapuesto a absoluto. Contra lo absoluto, (que es en principio "independiente, in-condicionado, in-determinado) lo finito viene caracterizado por su dependencia de algo, de alguna otra cosa que lo limita (Espinoza Eth.). Conocer, ya sea como el puro hecho de conocer, ya sea como contenido concreto, implica, pues, referencia a un algo que es conocido.

El conocimiento es siempre, pues, un conocimiento de algo, aun cuando no presupongamos en qué consiste ese algo al que se refiere siempre de partida el conocimiento. Hay en el conocimiento un referirse, que sin embargo no es inmediato, sino que procede a través de la sensación. Sensación (intuición) y conocimiento (concepto) son las dos caras de una misma moneda, no pueden existir la una sin la otra (Kant KrV). Las intuiciones sin conceptos son ciegas, los conceptos sin intuiciones están vacíos (Bermejo Barrera 1987).

En cuanto cada concepto concreto se refiere (en el juicio) a una intuición (o bien en cuanto el concepto puro se refiere a la intuición pura) es lícito decir que funciona como predicado de un sujeto. Sujeto nombra aquí lo que subyace (hypokéimenon, subiectum: Gadamer 1998), lo óntico en cuanto representación o intuición que acontece en la sensibilidad. De este sujeto decimos que "es" algo y ese algo lo caracterizamos mediante un concepto (pero no un "mero concepto" sino un concepto que es regla de constitución de la intuición y forma de la misma, es decir, que expresa el ser, la forma, el eîdos, del sujeto acerca del cual el juicio dice algo). A cada sujeto, en virtud del "es", no puede corresponder, por tanto, más que un concepto posible, en tanto que el concepto expresa el ser del sujeto, lo que el sujeto, verdaderamente "es" (A es B).

En la medida que decimos que sólo pueda existir un concepto (no un mero concepto) válido para cada sujeto, una constitución válida, una estructura que consiste en el ser de ese sujeto, decimos también que existe "objetividad". Ahora bien, en cuanto válidos, todos los conceptos, todos los predicados posibles deben constituir una unidad, deben ser compatibles unos con otros, de manera tal que, al igual que existe una y sólo una forma "objetiva" para cada representación, exista también un único sistema o conjunto de predicados válido para lo que existe (Martínez Marzoa 1989).

Lo que tienen de común todos los predicados válidos que, como hemos visto forman conjunto unos con otros, es que, de iure pueden considerarse como enunciados de un enunciante único. Este único enunciante es también en cierto modo el sujeto (trascendental) de todos los predicados posibles, por cuanto todos se dan en él. De esta forma, se produce una aparente paradoja: el sujeto (conjunto de predicados que dicen en general o en cada caso en qué consiste el ser) no coincide con el sujeto (el algo al que se refiere el conjunto de enunciados): el sujeto, en definitiva, no es el sujeto (Martínez Marzoa 1995, Fernández Liria 1998).

Pero si el caso es paradójico no resulta menos cierto que se trata de una paradoja aparente. En primer lugar, afirmar que el sujeto no es el sujeto viene a ser lo mismo que establecer que lo ontológico (el qué) no coincide ni puede coincidir nunca con lo óntico (el de qué), lo cual constituye el trasfondo de la consideración del conocimiento como validez, como possibilitas o forma de las cosas. En segundo lugar, que el sujeto no sea el sujeto viene a ser algo así como que no hay sujeto, algo así como que el sujeto que hemos definido como enunciante único no es nada ni nadie. Es un cero, un vacío, una nada que se proyecta sobre las cosas (Fernández Liria 1998) para saber lo que las cosas son, pero que, como no es nada, no modifica en nada las cosas, no las altera excepto en el sentido de que las hace conocidas.

Que el sujeto no sea el sujeto hace imposible, en resumidas cuentas, el tránsito de lo ontológico a lo óntico, estatuye lo óntico como un contenido dado al conocimiento, algo con lo que el conocimiento se encuentra, algo que el conocimiento ignora y quiere saber lo que es. Establecer lo óntico como un hecho,

12. Vide not. 9. 
como algo que viene dado para el conocimiento, equivale en cierto modo a considerar lo óntico como lo creado (Ídem), aquello de lo que en cualquier caso hay que dar cuenta (el de qué), aquello que se sabe que es algo, aunque en principio no se sepa exactamente lo que es.

Si de alguna manera supusiéramos, por el contrario, que el sujeto, esto es, el sujeto cognoscente en general, ese sujeto que hemos caracterizado como una nada, es a su vez el contenido de todo posible juicio, que el "ser" lógico tiene potestad para enseñorearse de la realidad convirtiéndose él mismo en la totalidad de las cosas, en ese caso no estaremos hablando ya de la realidad como un contenido que le viene dado al conocimiento, sino de que el conocimiento, lo ontológico, es capaz de generar lo óntico en sus infinitas determinaciones. Cada una de estas determinaciones que acostumbramos a llamar lo real se convierte de esta manera en un "momento" del ser absoluto, sin realidad efectiva, también en el sentido clásico, por cuanto lo ente no sería en sí, sino en lo absoluto. De este modo, el conocimiento al tratar de las cosas no estaría en realidad tratando de las cosas, sino tratando de sí mismo, no con la pretensión de conocer, sino con la de haber conocido siempre desde el principio. El conocimiento sería en tal caso no ya una ignorancia que pretende conocer (sólo sé que no sé nada), sino una ignorancia que pretende haber conocido de antemano, una ignorancia que persevera en su ser (Fernández Liria 1992, 1998).

Tiempo tendremos más delante de señalar qué clase de ignorancia es ésta y cómo trabaja en Arqueología. De momento, nos interesa más detenernos en un hecho que se ha introducido como de rondón en la argumentación anterior. La radical distinción entre la esfera de lo óntico y la de lo ontológico supone, se ha dicho, que en cierta medida lo ontológico se encuentra ya siempre de antemano con lo óntico y trata de conocerlo. ¿No es esto una forma de creacionismo, de creacionismo puramente filosófico?

Probablemente sí. Y probablemente también la Ciencia, en cuanto aplicación a lo óntico del conocer válido, ha trabajado desde siempre con este mismo supuesto: el que afirma que el mundo está ahí, como si procediese de un acto de libre de creación. ¿Cabe escandalizarse de ello? Seguro que no, porque no se está diciendo en modo alguno que el mundo, efectivamente, haya sido creado, sino que, para responder al problema de la validez en general, en el caso de la Filosofía, y para poder establecer sistemas de validez particulares, en el de la Ciencia, ambas tienen que proceder suponiendo que el mundo ha sido creado (lo que no implica que haya tenido que ser creado tal como lo conocemos, es decir, no se excluye por ello de raíz el evolucionismo).

Que el mundo ha sido creado no es, evidentemente, para la Ciencia más que una metáfora. Pero si el término metáfora parece demasiado literario o desagrada en demasía a los detractores del "giro lingüístico", puede sustituirse por el de "supuesto metodológico" que parece más apropiado a la Filosofía y a la Ciencia". El resultado será el mismo, porque apunta en la misma dirección, y esa dirección coincide con la consideración siguiente: aquello a lo que en verdad se ha opuesto siempre la Ciencia (y con ella, debería haberlo hecho también la Arqueología) no ha sido al creacionismo, sino al panteísmo, esto es, a la pretensión de que todo es en Dios y de que ese Dios que llamamos el Conocimiento o el Concepto puede sacarse de la manga como por ensalmo todo un mundo que no consiste más que en su propio despliegue (Ídem).

13. Va sobreentendido que el contenido de lo que aquí consideramos como creacionismo no coincide con el uso (lícito) que J. L. Escacena (e. p.) hace de la misma palabra en el trabajo que sirve de excusa al nuestro, un uso que se restringe a la vertiente religiosa del término. No está de más considerar, no obstante que el creacionismo religioso, al menos el del cristianismo, es también una respuesta clara al panteísmo (infra), y no sólo a la vertiente religiosa del panteísmo, sino también a la "racional" que decimos constituye el otro polo de la Ciencia. Respuesta que juega con ventaja, por cuanto al menos tuvo la valentía de considerar que el Concepto se hizo carne no en la totalidad del mundo, sino en una parte aparentemente insignificante de él que consiste en un niño nacido en un pesebre, que juega con la ventaja de convertir un uso espurio de lo racional en un misterio (Fernández Liria 1998). 


\section{ARQUEOLOGÍA Y PANTEÍSMO. UN MATRIMONIO FELIZ}

Todo lo anterior puede parecer demasiado abstracto además de demasiado improbable. En efecto, nadie afirma hoy abiertamente que lo real y efectivo sea en sí poco más que un despliegue de lo lógico, un darse lo mismo de otra manera, el resultado de la paciencia de un Concepto (Lebrun 1972), que despliega desde sí todas y cada una de sus infinitas determinaciones para acabar conociéndose a sí mismo como Absoluto. Nadie afirmaría con Hegel (Phä), a riesgo de ser tomado por loco, que el Ser verdadero contiene en sí todo lo real como despliegue óntico de sí mismo.

Pero que algo no se afirme abiertamente no quiere decir que se niegue, sino más bien que lo mismo se puede afirmar y de hecho se está afirmando de forma encubierta. En verdad, todo o casi todo lo que la teoría arqueológica en sus diferentes versiones parece haber establecido, también después de su supuesta "pérdida de la inocencia" (Clark 1973), es que, efectivamente, el sujeto (óntico) al que se aplica no es más que una modalidad del único sujeto (lógico) posible ${ }^{14}$.

Este único sujeto (lógico) posible no siempre coincide exactamente con el sujeto absoluto hegeliano, tal cual, sino más bien con diversas versiones "domésticas" y "domesticadas" del mismo. Las distintas versiones del Concepto hegeliano parecen competir entre sí en la pretensión de constituirse en el auténtico ser de las cosas, un ser cuyo contenido absoluto es a veces una supuesta dialéctica (Kofler 1974, Valverde Mucientes 1979), propia del Materialismo (Histórico) (Mcguire 1992), otras un cierto concepto de evolución como progreso indefinido llamado "procesualismo" (Johnson 2000), otras un aún más supuesto "círculo hermenéutico" que contiene en sí la comprensión del todo como contexto arqueológico (Shanks y Tilley 1992) y que se expresa a menudo en la pretendida negociación y renegociación del significado de la Cultura Material en torno a formas de "poder" social en el fondo muy foucaltianas (Tilley 1990).

En esta competencia, las diferentes versiones de lo absoluto se cruzan airadas acusaciones de materialismo o de idealismo (según el caso), probablemente sin que ninguna de ellas haya alcanzado a comprender en qué consiste ser materialista o ser idealista en Filosofía ${ }^{15}$ (hasta el punto de que llega a hablarse, por ejemplo, de un imposible "idealismo objetivo") ${ }^{16}$, sin reparar seguramente en que todas ellas son igualmente idealistas en el sentido panteísta descrito que es además el único posible.

14. Pese a las críticas vertidas aquí a diversas “escuelas” teóricas, no podemos ignorar las valiosas aportaciones de índole teórica, metodológica y práctica que muchas de ellas ha introducido en el acervo común de la teoría y la práctica arqueológicas. Tal vez sea el momento de recordar, para evitar malentendidos más que nada, que estamos ensayando ahora un enfoque filosófico y que, con arreglo a éste, nuestra crítica se dirige tan sólo a los aspectos más generales de cada "paradigma”, o lo que es o debería ser entendido como lo mismo, que se trata de una crítica de las bases ontológicas que cada uno de estos paradigmas asume o parece asumir.

15. Cfr. Gutiérrez Lloret (1997), aunque sólo como un ejemplo de tantos posibles que en nada desmerece el valor de la obra, porque esta consideración simplista del materialismo como reconocimiento de una realidad exterior, según la cual hasta Hegel podría ser llamado materialista, está lo bastante extendida (uide infra nuestras críticas a Bate 1998) como para culpar a nadie de ella. Tampoco nos parece que acierte al respecto I. Hodder (1987) quien plantea la imposibilidad del materialismo como consecuencia de la necesidad que tiene el investigador de contar con ideas en la labor de interpretación histórica ¿? Algo más ajustada resulta, en cambio, la sucinta definición proporcionada recientemente por G. Aranda (1999), cuya propuesta teórica se desarrolla precisamente en torno a una idea muy clara de lo que deba ser el materialismo, a la que tal vez le sobre la socorrida dialéctica, sin cuyo concurso probablemente no perdería gran cosa.

16. Kofler (1974). Resulta un tanto sonrojante, especialmente para alguien tan lego en la materia como un arqueólogo, tener que recordar que no se da en Hegel nada parecido a un "idealismo objetivo", por cuanto el supuesto objeto al que se refiere el Ser no es sino un momento de su propio itinerario conceptual, es decir, en tanto que para el Ser no existe algo verdaderamente otro. No cuadra de ningún modo la definición de idealismo objetivo para un sistema que trata no de un objeto exterior, sino de un sujeto absoluto, que ciertamente no niega la existencia de lo "material", pero que reduce esta existencia a un mero ser en el Concepto, privándola así de toda posibilidad. Resulta del mismo modo evidente que tampoco se da en Kant un idealismo subjetivo (a menudo entendido como paso necesario para la constitución hegeliana del idealismo objetivo), pues ya se ha dicho que el sujeto transcendental consiste precisamente en no ser sujeto. Lo que hay, lo que siempre ha habido en Kant, es, pues, un "idealismo trascendental" (supra) cuyo sujeto no coincide con nada antropológico o psíquico. 
Fundamentar convenientemente el conjunto de tesis que acabamos de plantear nos llevaría seguramente muy lejos, por lo que de momento, por razones de espacio, nos contentaremos con presentar algún ejemplo ilustrativo.

No nos detendremos especialmente en el malentendido kantiano que da lugar al neopositivismo y a la "New Archaeology", consistiendo como consiste ese malentendido en una lectura restrictiva (aunque posible) del apriori como característica exclusiva de aquel conjunto de juicios (los de la física matemática) que se tienen como los únicos especialmente válidos (recuérdese al respecto lo que se dijo acerca de la diferencia entre establecer que el conocimiento es posible a priori o, por el contrario, que el conocimiento a priori es posible).

Tal vez por lo mismo, la Nueva Arqueología, si es que una vez existió algo como tal, ha tenido pretensiones de cientifismo, y cierto es que estuvo cerca, pero se empeñó no sólo en el malentendido kantiano que acabamos de citar, sino también y sobre todo en la consideración del "proceso cultural" como factotum explicativo que vino de una forma muy "panteísta" a sustituir a la explicación misma de los hechos que en buen positivismo debía haber presidido su constitución como ciencia dura. Hoy pena sus "culpas" ${ }^{17}$ convertida, al menos en parte, en una Arqueología Cognitiva (Renfrew y Zubrow 1994) que pone el énfasis, ocupada como estuvo durante tanto tiempo en el estudio de la extensión, en cierta forma de psicologismo que parece atender a la otra cara (el pensamiento) de la dogmática clásica que subsiste a su planteamiento.

Tampoco podemos demorarnos en explorar la inconsistencia interna de la crítica contextualista a lo anterior (Hodder 1988), una crítica que se basa en algunos hallazgos supuestamente innovadores acerca de que es el contexto el que explica a cada una de sus partes (y aún se le llama a esto un proceder dialéctico) y que pudo parecer muy interesante para el público anglosajón al que se dirigía la obra primera y señera de I. Hodder (Ídem), poco acostumbrado como estaba ese mismo público a un proceder tradicional de la Arqueología que consistía precisamente en eso.

Cierto es que a esta constatación inicial se han venido sumando otras, como el sorprendente descubrimiento en el mismo lugar de la "talla" filosófica de Collingwod o la aún más sorprendente inclusión en un todo mal compuesto de la sobredeterminación althusseriana, la estructuración de Giddens y la microfísica del poder foucaltiana (Shanks y Tilley 1992), por no citar más que tres elementos que se compadecen mal entre sí y cuyo único punto de unión parece ser una mal explicitada unidad esencial entre objeto y sujeto de conocimiento muy del estilo hegeliano.

Nos hemos prometido, por otra parte, no entrar en consideraciones de fondo acerca de la Arqueología Evolucionista (cfr. Maschner (ed.) 1996, Rindos 1984, Escacena Carrasco e. p.), pero convendrá, por no dejarla al margen, considerar aquí que puede constituir un planteamiento consistente en tanto no se empeñe en confundir el conocimiento como ser o estructura de las cosas (que ella misma aplica a las cosas) con el psicologismo o subjetivismo que se desprende de considerar la otra forma posible de conocimiento: aquel hecho ofactum que se encuentra en lo real y que es sustancialmente un hecho biológico. A condición también, como con sagacidad ha visto W. Lütterfelds (1999), de considerar aquello que es el conocer como una categoría que, como cualquiera en la que consisten los conceptos, es difícil de naturalizar, incluso si uno tiene el ingenio y la capacidad intelectual de K. Lorenz (1984).

Nos detendremos un poco más en la consideración de la propuesta que plantea la "Arqueología Social”, tan sólo en tanto ésta es la que parece haber encontrado un mayor eco en el panorama arqueológico andaluz en el que goza de una muy buena salud. Es una postura que además requiere una especial atención al hilo de lo que nos viene interesando en nuestra exposición, por cuanto opera con mayores pretensiones de completud y de coherencia filosófica que las anteriores (Bate s. f., Ídem 1998).

17. No es que queramos culparla de nada, sino que la misma New Archaeology partía de la constatación de su propia pérdida de inocencia (Clark 1973). 
En la Arqueología Social, no en toda ella, pero en una parte importante al menos, reside aparentemente lo fundamental de aquello que se llamó "lo mejor del marxismo", como sinónimo de un humanismo que, pretendiendo, al igual que su otra cara, la Teoría Crítica, hacerse eco de lo sustancial del pensamiento de Marx, ha conseguido las más de las veces actuar en realidad como vocero de Hegel (Bate y Nocete 1992).

Dicho lo anterior, añadiremos que, por evidentes razones de espacio, tan sólo podemos ocuparnos, y no en profundidad, de aquellos aspectos teóricos de la Arqueología Social que nos parecen esenciales al hilo de lo aquí tratado.

Se parte del hecho de que la realidad exterior existe de forma independiente a su conocimiento (Bate 1998), lo que en principio no resulta incompatible con nuestro planteamiento. Hemos afirmado, no obstante, que el ser de las cosas no reside en las cosas mismas, sino en su conocimiento, lo que una vez más no debe interpretarse como que este ser sea algo exclusivamente en nuestra mente, sino que el conocimiento de las cosas coincide esencialmente con lo que las cosas son. Evidentemente, para que algo sea efectivo para el conocimiento debe ser pensado por éste, pero como el conocimiento no es nada ni nadie en concreto, la conclusión perentoria es que las cosas son como no necesitando ser pensadas (Peña García 1974).

El ser de las cosas consiste pues, en su posibilidad, su estructura (que nos es ofrecida en el conocer), en esa nada que viene a ser una estructura ausente, una estructura que en verdad no es nada, porque, por usar las palabras de Althusser (1976), reside, no en un soporte oculto y esencial a las cosas, sino en sus propios efectos.

Suponer, por el contrario, que existe algo inherente a las cosas por el mero hecho de ser cosas es suponer la cosa-en-sí, de la cual el conocimiento no sería sino representación, siendo el criterio de veracidad no el conocimiento mismo sino la cosa exterior. De este modo, la legitimidad del discurso consistiría en su correspondencia con la realidad exterior y se obtendría en la contraposición directa entre el conocimiento de la cosa y la cosa misma.

Pero se ha dicho que el conocimiento se refiere a las cosas no de un modo inmediato, sino a través de los conceptos (en el mismo sentido en que la ciencia experimental no se enfrenta directamente al fenómeno, sino que lo piensa -aísla, aprehende- a través de sus instrumentos (Bachelard 1985), y luego, por supuesto, lo conceptualiza, lo matematiza). El conocimiento actúa, en efecto, examinando la pertinencia de los conceptos (Husserl 1977), comparando conceptos de cosas con conceptos de cosas y no cosas con conceptos, comprobando si en esta comparación cada concepto forma contexto con los demás (en este sentido puede decirse que la "verdad" no reside en nada externo, sino que es index sui (Fernández Liria 1992).

Suponer que el conocimiento se dirige de forma inmediata a las cosas es, por tanto, suponer que existe algún tipo de vínculo entre ambas instancias más allá de aquello en que consiste el "es" (la síntesis del juicio); es suponer que existe un tipo de conocimiento más potente que puede hacerse cargo de la cosa sin mediación de los conceptos o a través de un único concepto absoluto. Pero la única manera efectiva de que eso ocurra es que la exterioridad en que consiste ese algo no sea sino un desplegarse o un desdoblarse del conocimiento, una creación del sujeto cognoscente, pero de un sujeto cognoscente que no es éste o aquél, ni siquiera un sujeto abstracto finito, como el kantiano, sino que es un sujeto absoluto.

Regresamos, por tanto, al panteísmo al haber cerrado el círculo incongruencias que conduce a que lo efectivamente existente en el "exterior" no sea más que la exteriorización de un interior, un despliegue lógico de lo mismo. No resulta, por ello, extraño que los defensores de este materialismo peculiar consideren la obra de Hegel como el ejemplo más acabado de su propia doctrina ${ }^{18}$. Es probable, por tanto, que cuando afirman, refiriéndose a Marx que no está muerto ni enterrado, que "un fantasma recorre Europa" estén en realidad hablando del fantasma de Hegel (Bate y Nocete 1992).

18. Bate 1998, lo reconoce de forma explícita, por lo que resulta sintomático de este proceder en Arqueología. 
El resultado internamente inconsistente a que se llega por este camino panteísta no es consecuencia sino de la propia inconsistencia que supone el establecer una conexión posible y necesaria entre lo lógico, lo ontológico (léase óntico) y lo epistemológico (Bate 1998). A lo que parece, es necesario refugiarse de nuevo en la cuidadosa distinción que debe establecerse entre lo óntico y lo ontológico, única manera de salvaguardar la exterioridad irreductible de las cosas, si lo que de verdad buscamos es un espacio en el que las cosas se muestren como verdaderamente son y no como un momento en el itinerario lógico que lleva de regreso al Concepto.

Se nos objetará, no nos cabe duda, que el regreso que el improbable Materialismo Dialéctico propone no es un regreso a lo mismo, sino a una versión depurada de lo mismo que consiste en su superación dialéctica (Valverde Mucientes 1979). Esto no es seguramente más que forma de empeorar las cosas, porque dicha superación opera a costa de introducir lo negativo (contradicción) de lo lógico en medio de las positividades de lo real, nihilizándolas (también en un sentido moral). Pero en lo real, suponiendo una vez más que se pueda hablar de alguna manera de lo real en sí, no existe nada que sea estrictamente lo contrario de cualquier otro. En lo real nada opera tal que en la lógica como un encuentro de fenómenos negativos y positivos (Kant 1992). No, en lo real sólo existen fuerzas positivas que se implementan o se anulan, no consistiendo el ser de ninguna de ellas en ser lo contrario de la otra.

No se puede decir de ninguna manera, por utilizar un esquema simple, que el rozamiento contra la superficie de la mesa de billar sea la negación o lo contrario que el movimiento de la bola, siendo la detención del mismo algo como la superación dialéctica de ambos. El ejemplo no es tan absurdo como el mismo planteamiento que presupone, por ejemplo, que la lucha de clases es el medio dialéctico en que se produce el encuentro entre la clase obrera y la burguesa, el ser de cada una de las cuales se reduce a mera afectación negativa de la otra (Fernández Liria 1998). Pero en la Historia nada opera en verdad mediante contradicciones, que son, hay que recordarlo, categorías pertenecientes a la mera lógica (y que como tales no incumben al Conocimiento, sino a la Razón).

Lo que subyace en todo el malentendido acerca de la dialéctica es que al poner sobre sus pies (se supone que Marx) aquello que estaba de cabeza (en Hegel), el resultado no puede haber sido sino lo mismo (Hegel) puesto del derecho (Althusser 1976). En otras palabras, que el logro de Marx no consiste en haber puesto del derecho la dialéctica hegeliana, ni en haber extraído un hallazgo metodológico esencial de un contexto idealista para devolverle su prístina pureza materialista (contra Bate 1998).

Bastó simplemente con "leer El Capital" (Althusser y Balibar 1978) para caer en la cuenta de que en esta obra nada funcionaba de modo dialéctico, de que lo que en realidad estaban puestos en ella eran los elementos constitutivos (las condiciones de posibilidad) de la sociedad "moderna", cuya ley, sin referirse para nada a la dialéctica, dijo Marx haber descubierto ayudado por un consumo inmoderado (e insomne) de tabaco ${ }^{19}$. Y esos elementos constitutivos tienen una génesis histórica y se articulan en una estructura, en un ser, que el conocimiento aspira a establecer sin recurrir para nada al auxilio de las leyes de la dialéctica.

El quid de la cuestión está una vez en la estructura, en el eîdos, en la forma, en el ser, en esa estructura ausente en la que para nada interviene la dialéctica y que no es ni puede consistir más que en sus propios efectos. Conocer, también en Arqueología, consiste en dar cuenta de esa estructura, de ese sistema de conceptos conectados entre sí que arroja como saldo el ser de lo real histórico. Conocer no equivale, entonces, a desplegar un solo concepto más potente que se estima absoluto en tanto que verdadera realidad y del cual toda la fecundidad de lo material, incluida la Cultura Material, no es más que derivación necesaria, momento lógico, ser en otro (y por tanto no-ser).

19. En carta a F. Engels con fecha 14 de enero de 1885: "with an immense deal of tobacco”. Cit. en Fernández Liria (1998). 
¿Cómo se conoce la estructura y cuál es el criterio de veracidad de lo conocido? Lo más probable es que sea improcedente suponer que la estructura como tal estructura se pueda conocer sin más, simplemente porque ella misma es el conocimiento. En cuanto al criterio de veracidad no hay más que el que siempre ha habido en la Ciencia: el Método (cartesiano) ${ }^{20}$, la potencia de la deducción que no compara conceptos con cosas, sino que conceptualiza a partir del material sensible y compara, también en Arqueología, unos conceptos con otros, examinando la coherencia y la pertinencia de las conexiones propuestas, sustituyendo conceptos erróneos por otros acertados, volviendo sobre el material para construir documentos arqueológicos (experiencias válidas que no son en sí sino una clase peculiar de documentos históricos) que traten de explicar el registro no en referencia a un absoluto absolutamente explicativo (cualquiera que éste sea), sino en referencia a lo que las cosas son de forma eterna y necesaria, también en Arqueología, también en Historia.

Sólo de esta manera se podrá, parafraseando la conocida opinión de Descartes al respecto de Galileo ${ }^{21}$, decir que el arqueólogo "hace Filosofía mucho mejor de lo que es común, pues trata de examinar cuestiones arqueológicas por medio de razonamientos matemáticos", bien entendido que "matemático" no tiene aquí el significado vulgar de formalizados en leguaje lógico fregiano, sino el más amplio y filo-sófico de mathesis, de lo que no se olvida (la aletheia), de aquello que se enseña y que se aprende (Fernández Liria 1998), de aquello que opera no por meros conceptos, sino mediante conceptos (a priori) acerca del qué de las cosas; de aquello que consiste, al fin y al cabo, en la deducción de la possibilitas del ser de las cosas (históricas) ${ }^{22}$, una deducción ${ }^{23}$ que, como quiso Kant, comienza con la experiencia (válida), pero no consiste toda ella en la experiencia $(\mathrm{KrV}, \mathrm{A})$.

\section{A MODO DE CONCLUSIÓN: CIENCIA (TAMBIÉN ARQUEOLOGÍA) E IDEOLOGÍA}

En algún lugar queda dicho que una de las notas distintivas del panteísmo con respecto al conocimiento es que consiste precisamente en una cierta ignorancia sobre las cosas, por cuanto actúa pretendiendo haber sabido siempre de antemano. En cierta manera, esta ignorancia es el resultado de haber obviado la cesura, la insalvable distancia que separa lo óntico de lo ontológico, lo real de lo lógico. Pues bien, de algún modo puede decirse también que esta ignorancia, que no por serlo excluye la erudición, equivale a una forma de ideología (Fernández Liria 1998).

Ideología se opone aquí a Ciencia como ignorancia se opone a saber, en el sentido de que toda pretensión científica guiada por la ideología acaba desembocando en la clase de ignorancia propia del sujeto absoluto. Esto no significa desde luego que el científico deba ser desinteresado o poco comprometido, sino simplemente que debe ser desinteresado o poco comprometido al respecto de su objeto específico de conocimiento, que

20. A menudo se ignora que el Discurso del Método de Descartes (Disc. Méth.) es menos una reflexión metafísica que un preámbulo necesario a la óptica, los meteoros y la geometría que venían a continuación y que ya no suelen editarse.

21. "(Galileo) hace filosofía mucho mejor de lo que es común, pues trata de examinar cuestiones físicas por medio de razonamientos matemáticos", en carta a su corresponsal M. Mersene, con fecha 11 de octubre de 1638. Valga, además, este ejemplo como prueba de que casi toda la metafísica de Descartes puede inscribirse entre los ejes de las coordenadas a las que dio nombre.

22. Que sepamos, los únicos intentos teóricos en este sentido han venido en España de la mano de los historiadores de la Antigüedad: J. C. Bermejo Barrera (1987, 1989), desde una "Historia Teórica" explícitamente kantiana (que es a su vez de las pocas en proponer que el sujeto cognoscente al menos en Historia, no coincide con el psicológico, pero que se resiste, no obstante, tal vez por el prejuicio de la formalización, a considerar ciencia a la Historia) y G. Chic García (1990, 1995), para quien la clave estructural está en la contraposición de formas históricas de pensamiento (logos y mito) y que propone como paradigma interpretativo histórico un "sistema estructural de horizontes mentales integrados".

23. Como puede intuirse, esta deducción tiene poco que ver con la tan traída como mal entendida (por los arqueólogos) cuestión del "método hipotético-deductivo". 
debe pretender, sin más, conocer. Tampoco quiere decir que el interés por el conocimiento (filo-sofía) proceda de un arrebato de puro afán por conocer. Toda forma de conocimiento científico (también en Arqueología) procede primariamente de un interés ideológico (Ídem). Pero la Ciencia, al mismo tiempo que una ignorancia de partida que se esfuerza en conocer, es también una ideología de partida que procura desinteresarse en el ejercicio de su cometido, pues este consiste o debe consistir poco más que en el propio conocer. Ocurre, como se ve, que al igual que existe un abismo insalvable entre lo óntico y lo ontológico, hay una brecha sin posible sutura entre lo científico y lo ideológico ${ }^{24}$.

Es por ello que pudo Kant en su día fundamentar con relativa independencia la "metafísica" del conocimiento de la "metafísica" de la decisión. Metafísica en este caso indica aquello que tiene que ver con el ser, lo que de por sí viene a decir que ambos aspectos separados son al mismo tiempo el anverso y el reverso de la cuestión del ser. Ambos se refieren al ser, pero a modos diferentes e irreductibles del ser: el uno como validez cognoscitiva, el otro como validez decisoria (de la decisión). Irreductibles significa que ningún conocimiento puede fundamentar una decisión, y que ninguna decisión puede considerarse fundamento de conocimiento alguno (Martínez Marzoa 1994), aunque es evidente que ninguna decisión puede tomarse sin estar basada en cierta clase de conocimientos.

¿Quiere decir esto que cada uno es absolutamente libre de optar por su propio referente moral? Seguramente no, puesto que la validez en que consiste la decisión es una validez única en la que todas las decisiones deben formar, como ocurría con respecto a la validez en que consiste el conocimiento, un contexto unitario. Lo único que quiere decir, por tanto, es que el conocimiento no agota la totalidad del ser, que de lo ontológico en que consiste el conocimiento no puede desprenderse lo moral, o, en sentido contrario, que de lo que alguien ha llamado el "área valorativa" (Bate 1998) no puede desprenderse una "posición teórica" (Gándara 1994), cualquier cosa que esto signifique.

Ello no impide, no obstante, el hecho de que el conocimiento, desde el episodio bíblico de la serpiente, sea visto por quien toma en última instancia las decisiones como peligroso (recuérdese la suerte de Sócrates, o la que estuvo a punto de correr Galileo), al menos el conocimiento acerca de en qué consiste el ser de lo constituido como poder hegemónico. De ahí que hoy no inquiete a poder alguno el avance de las ciencias naturales, antes al contrario, pero que se intente por todos los medios posibles controlar la Historia y una Arqueología que se vacía de contenido histórico para convertirse en la gestión de los Bienes de Interés Cultural (eso que antes se llamaba Patrimonio Histórico, y obsérvese al respecto la meticulosidad administrativa con que se amputa cualquier referencia a lo histórico). Se trata en definitiva de impedir que la Historia y la Arqueología se constituyan en Ciencia (o bien de que si eso ocurre en el ámbito incómodo de lo académico, que al menos no trascienda los muros de la Universidad), para evitar, en definitiva, que ambas digan qué son las cosas en la Historia.

La respuesta a este orden de cosas no es desde luego una forma de ignorancia histórica contraria e igualmente ideologizada (que en cualquier caso puede ser utilizada por un poder de signo contrario). Tampoco una renuncia a la Historia como Ciencia, en la peregrina idea de que las ciencias son otros tantos recursos del poder constituido (se llegó a hablar de ciencias "burguesas" como contrapuestas a la ciencia "dialéctica") o una pretensión de Historia como retórica y contrapoder, como un conjunto de respuestas alternativas (feminista o populista, ecológica, étnica o folklórica) cuyo único objeto parece ser oponerse al poder en la batalla de lo cotidiano, como si el poder necesitara ejercerse en lo cotidiano para ser efectivo (Fernández Liria 1998).

24. La constatación y la demostración de esta doble ruptura de lo óntico y lo ontológico por un lado, y de lo cognoscitivo y lo moral, por otro, es a nuestro entender el auténtico legado de Kant, lo que queda de Kant, incluso después de la superación de la física newtoniana; incluso después de Darwin, incluso después de la disolución, en buena hora, del kantianismo. 
Hay, por descontado, también algo de panteísta y hegeliano en esto último que algún autor ha denominado con acierto "la ideología del portazo"(Fernández Liria 1992), porque lo que pasa por alto este tipo de planteamientos, heredero de una confusión mental que se llamó revolución del sesenta y ocho, es que el poder no es acción y reacción, sino sobre todo estructura, una estructura de poder (o varias estructuras históricas en cada caso) que el conocimiento puede decir en qué consiste (a eso dedicó Marx la última parte de su vida) ${ }^{25}$ lo que tal vez inquiete al poder constituido mucho más que todos los movimientos alternativos del mundo y sus correspondientes arqueologías. ${ }^{26}$

\section{BIBLIOGRAFÍA}

ALBIAC, G. (1979): De la añoranza del poder o consolación de la filosofía. Editorial Hiperión, Madrid. (2000): "Spinoza/Marx: el sujeto constructo", en Borradores y Adelantos. Fantasmas del XVII. http://cerezo.pntic.mec.es/galbiac/f15SpzMx.html.

ALTHUSSER, L. (1976): La revolución teórica de Marx. Editorial siglo XXI, México. D. F. ALTHUSSER, L. y BALIBAR, E. (1978): Para leer El Capital (contribuciones de Althusser y Balibar). Editorial Siglo XXI, México D. F.

ARANDA, G. (1999): "Algunas reflexiones sobre el proceso de investigación en Arqueología", Revista d' Arqueologia de Ponent 9: 87-94.

BACHELARD, G. (1985): La formación del espíritu científico. Editorial Siglo XXI, México. D. F. (Ed. original, 1938).

BATE, L. F. (1998): El proceso de investigación en Arqueología. Editorial Crítica, Barcelona.

(s. f.): Estructura general del proceso de investigación en Arqueología. Escuela Nacional de Antropología e Historia de México, México D. F.

BATE, L. F. y NOCETECALVO, F. (1995): "Marxismo y Arqueología. Un fantasma recorre la Arqueología (No sólo en Europa)", Arqritica 6: 7-13.

BELTRÁN FORTES, J. (ed.) (e. p.): Arqueología, fin de siglo. Sevilla.

25. Especialmente conflictivo para el pensamiento de Marx debió ser su encuentro tardío con el frío determinismo materialista de Spinoza, tal vez una de las razones por las que el tomo VI de El Capital quedó inédito. Tal conflicto parece haber girado en torno al núcleo duro del materialismo spinozista (y no debe olvidarse que el spinozismo había pasado por ser para una parte de la filosofía clásica alemana el paradigma más radical del materialismo),expresado en la categoría de subsunción real, finalmente suprimida por Marx, aunque en principio había sido formulada por éste en los términos de una "subsunción real del capital en el trabajo". El episodio debía constituir el último escalón (ya hoy dramáticamente presente) del desarrollo capitalista, un episodio en el que el trabajo deja de ser una mercancía generadora de plusvalía y se convierte todo él en mera plusvalía, es decir, en capital. Por lo tanto, no estará ya subsumido formalmente, sino realmente, en éste ultimo. La aceptación sin remilgos de las consecuencias últimas de tal categoría supone, sigue suponiendo, la eliminación de dos ideas "clásicas" y, valga la redundancia, "idealistas" de la tradición marxiana que provienen del hegelianismo: el finalismo teleológico del Espíritu absoluto y el libre albedrío inherente al mismo. Coincidimos con G. Albiac en el convencimiento de que es precisamente en torno a esta problemática donde debe procurar rehacerse el pensamiento político de una izquierda que no puede ya contentarse con parafrasear como siempre a Hegel. Al respecto de todo lo anterior, puede verse el lúcido (y amargo) comentario de G. Albiac, aún en borrador, pero generosamente lanzado a la red informática por el autor (Albiac 2000). La misma problemática ha sido tratada, y no es casualidad, por C. Fernández Liria (1992), quien pone el acento en lo perverso del rígido determinismo economicista que conduce al capitalismo avanzado y que amenaza con convertirlo en un (nuestro) yugo eterno. Es, en gran parte, porque las propuestas de la Arqueología Social no sólo ignoran, sino que, mucho nos tememos, ni siquiera imaginan el problema, por lo que nos parecen trágicamente trasnochadas. Subrayamos el adverbio y, por qué no, también el adjetivo y al tiempo esperamos que se nos disculpe la osadía.

26. De donde se deduce que la confusión que se constata actualmente en la disciplina arqueológica por lo que hace a la teoría puede superarse no meramente con un "rearme moral” (Domínguez Berenjeno 1996), sino también intelectual (Fernández Liria 1989). 
BERMEJO BARRERA, J. C. (1987): El final de la Historia. Ensayos de historia teórica. Editorial Akal, Madrid, 1987.

_ Replanteamiento de la Historia. Ensayos de historia teórica II. Editorial Akal, Madrid, 1989.

CHIC GARCÍA, G. (1990): Principios teóricos en la Historia. Editorial Gráficas Sol, Écija.

— (1995): Pensamientos universitarios. Editorial Gráficas Sol, Écija.

CLARK, D. (1973): “Archaeology: the loss of innocence”, Antiquity 47: 6-18.

DESCARTES, R. (Disc. Méth.): Discurso del Método. Alianza Editorial, Madrid (6 ${ }^{\mathrm{a}}$ edición), 1983.

DOMÍNGUEZ BERENJENO, E. L. (1996): "La verdad inexistente: Arqueología y reflexión filosófica", Spal 6: 9-22.

ESCACENA CARRASCO, J.L. (e. p.): "Darwin (in)comprendido. Evolución Humana y Prehistoria en la Tradición Académica Andaluza. Breve Análisis de una Paradoja”, en J. BELTRÁN FORTES (e. p.).

ESPINOZA, B. de (Eth.): Ética. Introducción traducción y notas de V. I. Peña. Editora Nacional, Madrid, 1980.

FERNÁNDEZ LIRIA, C. (1989): Volver a pensar. Una propuesta socrática a los intelectuales españoles. Editorial Akal, Madrid.

- (1992): Sin vigilancia y sin castigo. Una discusión con Michel Foucault. Ediciones Libertarias, Madrid. (1998): El Materialismo. Editorial Síntesis, Madrid.

GÁNDARA, M. (1994): "Consecuencias metodológicas de la adopción de una ontología de la cultura: una perspectiva desde la arqueología", en GONZÁLEZ y GALINDO (eds.).

GARCÍA, E. y MUÑOZ, J. (1999): La teoría evolucionista del conocimiento. Editorial Complutense, Madrid.

GARCÍA MORENTE, M. (1980): Lecciones preliminares de Filosofía. Editores Mexicanos Unidos, México D. F. ( $4^{\mathrm{a}}$ ed $)$.

GADAMER, H. G.(1998): El giro hermenéutico. Editorial Cátedra, Madrid.

GONZÁLEZ, J. y GALINDO, J. (eds.) (1994): Metodología y cultura. CONACULTA, México, D. F.

GUTIÉRREZ LLORET, S. (1997): Arqueología. Introducción a la cultura material de las sociedades del pasado. Universidad de Alicante, Alicante.

HAVELOCK, E. A. (1994): Prefacio a Platón. Editorial Visor, Madrid (ed. original, 1963).

HEIDEGGER, M. (1977): Phaenomenologische Interpretation von Kants Kritik der reinen Vernunft. Gesamtausgabe XXV, V. Klostermann, Francfort.

HEGEL, G. W. F. (Phä): Fenomenología del Espíritu. Fondo de Cultura Económica, Madrid, 1978.

- (Enz): Enciclopedia de las ciencias filosóficas. Alianza Universidad, Madrid, 1997.

HODDER, I. (1988): Interpretación en Arqueología. Corrientes actuales. Editorial Crítica, Barcelona.

HUSSERL, E. (1977): La idea de la fenomenología. Fondo de Cultura Económica, México D. F. (Ed. Original, 1907).

JOHNSON, M. (2000): Teoría arqueológica. Una introducción. Editorial Ariel, Barcelona.

KANT, I. (KrV, A y B): Crítica de la Razón Pura. Editorial Alfaguara, Madrid, 1978.

(1992) "Ensayo para introducir las magnitudes negativas en Filosofía", en Opúsculos de Filosofía natural. Alianza Editorial, Madrid.

KOFLER, L. (1974): Historia y dialéctica. Amorrortu Editores, Buenos Aires.

LÓPEZ BORGOÑOZ, A. (1995): "Sobre el objeto de conocimiento de la Arqueología", Actas del XXII Congreso Nacional de Arqueología, Vigo, 1993. Vigo: 333-336.

LEBRUN, G. (1972): La patience du Concept. Essai sur le discours hégélien. Ed. Gallimard, París.

LORENZ, K. (1984): "La teoría kantiana de lo apriorístico desde el punto de vista de la biología actual", en LORENZ, K. y WUKETITS, F. M. (Ed. original, 1941): 89-116.

— y WUKETITS, F. M. (1984), La evolución del pensamiento. Editorial Argos Vergara, Barcelona. 
LULL, V.; MICÓ, R.; MONTÓN, S. y PICAZO, M. (1990): "La arqueología entre la insoportable levedad y la voluntad de poder", Archivo de Prehistoria Levantina XX: 461- 472.

LÜTTERFELDS, W. (1999): "Una crítica transcendental a la teoría evolucionista del conocimiento", en GARCÍA, E. y MUÑOZ, J., pp. 114-130.

McGUIRE, R. (1992): A Marxist Archaeology. Academic Press, Nueva York.

MARTÍNEZ MARZOA, F. (1989): Releer a Kant. Editorial Anthropos, Barcelona. (1992): De Kant a Hölderlin. Editorial Visor, Madrid. (1994): Historia de la Filosofía (2 tomos). Editorial Istmo, Madrid ( $2^{a}$ edición revisada). (1995): Hölderlin y la lógica hegeliana. Editorial Visor, Madrid.

MASCHNER, H. D. G.(ed.), (1996): Darwinian Archaeologies. Plenum Press, Nueva York.

PACHO, J. (1999): "El a priori del saber y el saber del a priori en las teorías evolucionista y transcendental", en GARCÍA, E. y MUÑOZ, J., pp. 93-111.

PEÑA GARCÍA, V. I. (1974): El materialismo de Spinoza. Revista de Occidente, Madrid.

RENFREW, C. y ZUBROW, E. B. W. (eds.) (1994): The ancient mind. Elements of cognitive archaeology. Cambridge University Press, Cambridge.

RINDOS, D. (1984): The origins of agriculture. An evolutionary perspective. Academic Press, Orlando. SHANKS, M. y TILLEY, Ch. (1992): Re-constructing Archaeology. Theory and Practice. Routledge Ed, Londres y Nueva York.

TILLEY, Ch. (Ed.) (1990): Reading Material Culture. Structuralism, Hermeneutics and Post-Structuralism. Blackwell, Oxford.

(1990) "Michel Foucault: Towards an Archaeology of Archaeology", en TILLEY, Ch. (Ed.), pp. 281-347.

VICENT GARCÍA, J. M. (1992): "Evolucionismo e ideología", Arqritica 3: 8-12.

VALVERDE MUCIENTES, C. (1979): El Materialismo Dialéctico. El pensamiento de Marx y Engels. Editorial Espasa-Calpe, Madrid. 